\title{
Research on Network System Establishment of Lifelong Education under the Background of "Internet plus"
}

\author{
Hefei Li \\ North China University of Science and Technology, Tangshan, 063000, China
}

Keywords: Lifelong education, Lifelong learning, Internet plus.

\begin{abstract}
The internet is affecting people's work, life and study with unprecedented strength. At the same time, the construction of lifelong education system has become a social consensus. This paper discusses the system establishment advantages of lifelong education based on the internet and gives the key points of constructing lifelong education system under the background of the internet plus, including the establishment of internet platform, professional organizations and credit bank of lifelong education to provide some references for the relative researchers.
\end{abstract}

\section{Introduction}

With the deep development of Internet and modern electronic information technology, lifelong education is no longer empty talk. The learners can truly realize lifelong learning, receive education continuously, and improve their comprehensive cultural quality. Under the background of the deep integration of Internet and lifelong learning, lifelong education has been greatly developed and improved. The Internet refers to the interconnection of networks, forming a huge whole network. It has many advantages, such as high efficiency, convenience, low cost and huge amount of information. It has been rapidly implemented in our country as soon as it appears. With the continuous development of the Internet, China has entered the Internet era, according to last year's latest data. At present, the number of Internet users in China has exceeded eight hundred million. Interconnection is widely used in various fields. Especially in education, because of its strong advantage so that the learners can watch the video through the online search information, and other ways to complete the learning, so lifelong learning can be realized, and the deepening of integration with the internet background, the way people learn, thinking logic and learning habits were changed and then promote the development of modern education. The deep integration of the Internet and lifelong learning has had a positive impact on society and promoted the reform of lifelong education. The Internet is a new mode of information dissemination. It is the fourth media after newspapers, radio and television. At present, the Internet has become a trend, you can according to their actual work, study professional, teaching plan and curriculum arrangement. The impact of Internet on education involves teaching content, teaching methods, educational structure, and even the whole educational system. With the rapid development of Internet technology, lifelong education has entered the information age. In the process of promoting the development of Internet technology comprehensively, the innovation of lifelong education is not only beneficial to the realization of the all-round development of human beings, but also to the times of modern education. The internet provides technical support for lifelong learning, while the concept of lifelong learning also promotes the better development of internet technology.

\section{Advantages of Network Education}

More Abundant of Education Resources. The traditional mode of education information dissemination means backward, learning resource constraints, in this environment, a lot of very good learning resources may be missing or is only a small number of people, did not give full play to the 
advantage of educational resources. The rich resources of information covering different countries and of different levels and in different areas, as many as are the smoke of information resources sharing in the network platform, through the network can be all over the world schools, libraries, research institutions to link the formation of massive information database. Learners can use the Internet platform to search for information that they are interested in and want to know and use for themselves. Compared with network education, the traditional educational model is different in the aspects of updating and reserving knowledge. Traditional education cannot be reached, and the updating of network educational information has the characteristics of short time and rich content. The Internet combines text and images with hypertext to become a huge hypermedia information resource library linked to each other by a network. Learners are interested in this resource only by clicking on the link. In addition, the network education information from different ways, the computer terminal of the Internet will immediately reflect the relevant knowledge updates, more conducive to grasp the latest information resources for the first time in learning, the knowledge update speed. Lifelong education advocates the teaching content and form for target, practice, location, content and process of different, adopt flexible ways to make the educated according to the interests and needs to choose learning content and method. The diversity and flexibility of the network media enable the diversification of educational resources to be realized. The Internet era brings us convenience, and provides the common people with a way to broaden their horizons and enhance their knowledge.

More Flexible of Education Time. The network course breaks the time limit and becomes a new trend, which meets the requirement of the development of lifelong education. Online education platform is a means of obtaining information across time and space, breaking the traditional school wall model restrictions, as long as learners are willing to, and even anytime, anywhere to extract. In addition, online education is not bound by class teaching, and within the scope of the teaching plan, students have the freedom to choose the course of study. As the network education is not the traditional face-to-face education mode of teachers and students, it is not limited by time, space, content and progress. Learners can choose according to their own knowledge level and the ability to understand. The choice of learning methods can be achieved according to the learners' wishes. They can either step by step or learn by leaps and bounds. Learners can freely master the progress of learning, and combine their actual situation, develop learning plans, determine the content of learning. MOOC is a big online course. Compared with traditional courses, learners can choose their own courses according to their own time and place, so as to study autonomously. With the help of MOOC, more and more schools can open the door for anyone to study, and make lifelong education innovation possible, and fully solve the dilemma of differentiated and large-scale teaching. The flipped classroom teaching model has also received extensive attention. The standard process of overturning classes is composed of online learning, exercises, data learning, analysis, teacher answers, and so on. This model fully solves the problem of large-scale teaching, but also allows education to return to personalized teaching. The online learning model conforms to the individual learning characteristics of learners and is not bound by the constraints of time and space.

More Personalized of Education Content. Lifelong education takes people's needs seriously as the starting point. It is a necessary process to cultivate a complete human being. Lifelong education is an important manifestation of the way of self-distillation. Massive network resources can realize customized service of personal needs. The Internet era has overturned many traditional industries. Education is no longer confined to the classroom and the school, students can no longer fit, can adopt the methods and Strategies of learning ways and unique according to their own preferences, promote the development of personality and self-realization. Today's study is what I find and learn what I am interested in. Only the latter is more conducive to human development. Compared with traditional school education, network education has the advantages of globalization, personalization and low cost. The traditional school teaching only for the relative age groups of students, and network education teaching object covers all ages, as long as there is a willingness to learn can participate in, and is not affected by gender, education, occupation and identity restrictions. Electronic teaching plan and teaching activities of teachers is not only in the classroom, but through the network platform, 
their information resources, to the country and even the world, to provide learning resources for all types of learners. Network long distance education appears with the development of modern information technology. It is the main means of lifelong education in the era of knowledge economy. Study report the work or study also can be explored to become learning resources through online education activities, which not only helps to improve the learners' thinking training, but also can improve their spontaneous learning enthusiasm, learning together to achieve all walks of life, of all ages, all levels of learners.

\section{Strategies of Network System Establishment of Lifelong Education under the Background of "Internet +"}

Establish Internet Platform of Lifelong Education. Lifelong education, to a great extent, requires the opening and sharing of educational resources. The Internet platform just meets the needs of this sharing of resources, and it can provide the necessary technical support and theoretical support for the construction of lifelong education system. Therefore, in order to improve the development level of lifelong education in China, we can give full play to its advantages in the process of resource integration based on the Internet platform, so as to promote the development of lifelong education in china. We can on the Internet under the condition of moderate liberalization of the teaching resources management authority, and adopt flexible teaching resources integration application system, make organizations more able to get the support of life-long education. In the process of using the Internet platform, we can make full use of remote technology, home networking, learning terminals, learning websites, and provide convenient and fast learning resources and conditions for the masses of the people. We can build a large number of learning websites, using powerful servers, to provide the public with all kinds of data resources for online learning, to help them get more convenient learning conditions. At present, popular in the network multimedia courseware, network curriculum, computer assisted instruction equipment and so on, have become the platform and the way of lifelong education, helping many people get further learning opportunities. We can also incorporate some popular content into the media or platform, such as radio, internet and video. What's more, some entertainment programs can also increase the knowledge of history and literature in an appropriate way so that people can learn knowledge in the process of entertainment. In the development of Internet learning, the traditional learning channels can also be used for us.

Establish Professional Organizations of Lifelong Education. When necessary, we also need to set up certain lifelong education organizations and institutions so that they can be solely responsible for the related work of lifelong education, so as to provide better conditions for the implementation of lifelong education policy. We can be constrained by the perfection of laws and regulations, the construction of lifelong education system in China can bring very direct help. The construction of lifelong education system also depends on the reform of educational mechanism and the diversification of the subject of education, which is an important guarantee to promote the construction of lifelong education system. We can start from the legal system, education policy, management system and so on, and provide a good institutional condition for social education and lifelong education, which can greatly promote the development of lifelong education in China. In addition, we should make full use of the forces of change and promote the improvement and development of the domestic lifelong education system from the macro level, so as to clear up obstacles for the construction of lifelong education system and the improvement of the quality of education. Experience shows that our country wants to obtain the development of lifelong education in the future development process, should be based on the concept of innovation and development, the construction of lifelong education system in a prominent position, let it become a basic pillar of strategic human resources power, which is conducive to the development of China's lifelong education we need the existing teaching system to optimize the processing, and then in accordance with the requirements of the new lifelong education, to establish a new educational concept, to form a good relationship between communication for educators and students, institutional constraints let 
both sides behavior can be standardized tend to be appropriate, so as to better promote the development of lifelong education in China.

Establish Credit Bank of Lifelong Education. Credit bank refers to a person will be converted into the corresponding credits through various ways of learning the learning outcomes, stored to the relevant departments of the credit institutions, certification and evaluation by these institutions, when a person's credit accumulation to a certain number of levels, can be transformed into the corresponding degree or relevant qualification certificate. Credit bank is a bridge to build a lifelong education system. It effectively connects one's initial school education to later lifelong education. The establishment of credit bank is a breakthrough in the traditional education model, and an important measure to ensure the full course characteristics of lifelong education system. The aim and connotation of the digital lifelong education public service platform is based on the development of learners. According to the credit bank system, students need to complete a course to take certain credits, take part in skills training, research and credit, and then accumulate all the credits. At the same time, allow students to not follow the normal semester time for learning, but as the bank installment, learning time can be centralized can interrupt line. The purpose is through a variety of learning platform, docking sharing of educational resources, all education support services into lifelong education service system, the learners and the whole members of the society to the lifelong learning system in order to attract. One of the keys to building a truly learning society is to implement various forms of learning, including a variety of informal, formal and informal learning, and mutual recognition between formal and informal education. The establishment and implementation of credit system and the mutual recognition of credit through credit bank system are the necessary ways to promote lifelong learning. However, the mutual recognition of credit involves the institutions of education and needs to be coordinated by relevant state organizations.

\section{Conclusion}

The birth and development of the Internet, not only helps the learners to break the traditional education by the time and space constraints, but also provides the multitude learning resources so that the learners can learn whenever and wherever possible. The idea of lifelong education has also been formed. Under the background of "internet plus", more and more learners can enjoy the lifelong education to improve their comprehensive quality.

\section{Acknowledgements}

The paper is one of the results of Research Subject of Social Science Development of Hebei Province named "Current Situation Survey and Development Research of Lifelong Education Organizations in Hebei Province” (Grant No. 201603040155).

\section{References}

[1] Lu Qinghua. Research on Construction Strategy of Lifelong Education System Based on Internet [J]. Adult Education, 2015(11): 14-17.

[2] Zheng Liping,Yu Shi, Zhang Hua. Continuing Education Reformunderthe Background of the Deep Integration of the Network and Lifelong Learning [J]. Journal of Continuing Higher Education, 2015, 28(2): 7-11.

[3] Wu Lan. A Brief Discussion about Building Lifelong Education System in Bayannur City in the Internet Age [J]. Journal of Hetao College, 2016, 13(2): 82-85.

[4] Chen Yan. The Development Path of Distance Network Education in Colleges and Universities Based on Lifelong Education [J]. Adult Education, 2016(4): 76-80. 